\title{
Front Matter: Volume 8906
}

, "Front Matter: Volume 8906," Proc. SPIE 8906, International Symposium on Photoelectronic Detection and Imaging 2013: Laser Communication Technologies and Systems, 890601 (5 September 2013); doi: 10.1117/12.2042711

SDIE Event: ISPDI 2013 - Fifth International Symposium on Photoelectronic SPE. Detection and Imaging, 2013, Beijing, China 


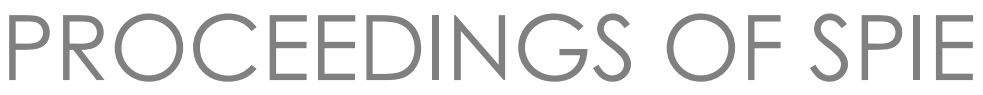

\title{
International Symposium on Photoelectronic Detection and Imaging 2013
}

\section{Laser Communication Technologies and Systems}

\author{
Keith E. Wilson \\ Jing Ma \\ Liren Liu \\ Huilin Jiang \\ Xizheng $\mathrm{Ke}$ \\ Editors
}

25-27 June 2013

Beijing, China

Organized by

Photoelectronic Technology Committee, Chinese Society of Astronautics • Tianjin Jinhang Institute of Technical Physics (China) - Science and Technology on Low Light Level Night Vision Laboratory (China) • Science and Technology on Optical Radiation Laboratory (China) • Science and Technology on Electromagnetic Scattering Laboratory (China)

Sponsored by

SPIE • The Optical Society • European Optical Society • Chinese Society of Astronautics

Published by

SPIE

\section{Volume 8906}


The papers included in this volume were part of the technical conference cited on the cover and title page. Papers were selected and subject to review by the editors and conference program committee. Some conference presentations may not be available for publication. The papers published in these proceedings reflect the work and thoughts of the authors and are published herein as submitted. The publisher is not responsible for the validity of the information or for any outcomes resulting from reliance thereon.

Please use the following format to cite material from this book:

Author(s), "Title of Paper," in International Symposium on Photoelectronic Detection and Imaging 2013: Laser Communication Technologies and Systems, edited by Keith E. Wilson, Jing Ma, Liren Liu, Huilin Jiang, Xizheng Ke, Proceedings of SPIE Vol.8906 (SPIE, Bellingham, WA, 2013) Article CID Number.

ISSN: 0277-786X

ISBN: 9780819497758

Published by

SPIE

P.O. Box 10, Bellingham, Washington 98227-0010 USA

Telephone +1 3606763290 (Pacific Time) · Fax +1 3606471445

SPIE.org

Copyright (C) 2013, Society of Photo-Optical Instrumentation Engineers.

Copying of material in this book for internal or personal use, or for the internal or personal use of specific clients, beyond the fair use provisions granted by the U.S. Copyright Law is authorized by SPIE subject to payment of copying fees. The Transactional Reporting Service base fee for this volume is $\$ 18.00$ per article (or portion thereof), which should be paid directly to the Copyright Clearance Center (CCC), 222 Rosewood Drive, Danvers, MA 01923. Payment may also be made electronically through CCC Online at copyright.com. Other copying for republication, resale, advertising or promotion, or any form of systematic or multiple reproduction of any material in this book is prohibited except with permission in writing from the publisher. The CCC fee code is 0277-786X/13/\$18.00.

Printed in the United States of America.

Publication of record for individual papers is online in the SPIE Digital Library.

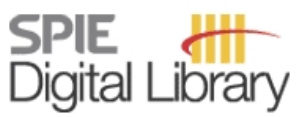

SPIEDigitalLibrary.org

Paper Numbering: Proceedings of SPIE follow an e-First publication model, with papers published first online and then in print and on CD-ROM. Papers are published as they are submitted and meet publication criteria. A unique, consistent, permanent citation identifier (CID) number is assigned to each article at the time of the first publication. Utilization of CIDs allows articles to be fully citable as soon as they are published online, and connects the same identifier to all online, print, and electronic versions of the publication. SPIE uses a six-digit CID article numbering system in which:

- The first four digits correspond to the SPIE volume number.

- The last two digits indicate publication order within the volume using a Base 36 numbering

system employing both numerals and letters. These two-number sets start with 00, 01, 02, 03, 04, $05,06,07,08,09,0 A, 0 B \ldots$. 0Z, followed by 10-1Z, 20-2Z, etc.

The CID Number appears on each page of the manuscript. The complete citation is used on the first page, and an abbreviated version on subsequent pages. Numbers in the index correspond to the last two digits of the six-digit CID Number. 


\title{
Contents
}

\author{
xiii Conference Committee \\ $\mathrm{xV}$ Introduction
}

\section{LASER COMMUNICATION TECHNOLOGIES AND SYSTEMS}

890602 Optimal design of a new type space laser communication optical system [8906-1] P. Yan, X. Deng, H. Zhang, Xi'an Institute of Optics and Precision Mechanics (China)

890603 Design and implementation of omni-directional light source and receiving system used in underwater wireless optical communication [8906-2]

J. Rao, W. Yao, Naval Univ. of Engineering (China); N. Chen, Hudongzhonghua

Shipbuilding Co., Ltd. (China)

890604 Optical power influence on PLL of BPSK homodyne receiver [8906-3]

H. Guo, L. Zhang, B. Wang, W. Zhang, China Academy of Space Technology (China)

890605 A new chromatic dispersion compensation method based on genetic algorithm [8906-4] C. Liu, J. Qin, Z. Huang, Y. Zhang, National Univ. of Defense Technology (China)

890606 LDPC codes in wireless optical communication application [8906-7]

G. Qi, X. Yang, W. Fan, Univ. of Electronic Science and Technology of China (China)

890607 Variable structure multiple model tracking for airborne laser communication systems [8906-10]

Y. Cao, J. Guo, L. Huang, Chongqing Univ. of Technology (China)

890608 Study on simulation and experiment of laser micro-Doppler effect for detecting complex vibration [8906-12]

S. Yuan, Yantai Univ. (China); J. Zhang, Automotive Engineering Vocational College

(China); M. Liu, J. Zhang, Yantai Univ. (China)

890609 Effect of beam wander on the scintillation characterization for multiple beams [8906-13]

W. Wu, Anhui Institute of Optics and Fine Mechanics (China), Univ. of Chinese Academy of Sciences (China), and National Univ. of Defense Technology (China); Q. Sun, G. Ren, Y. Ning, R. Du, National Univ. of Defense Technology (China); Y. Wu, Anhui Institute of Optics and Fine Mechanics (China)

8906 OA The non-continuous optical signal identification and data storage on the case of atmospheric disturbances [8906-14]

S. YU, Y. Liu, J. Ma, L. Tan, Harbin Institute of Technology (China) 
8906 OB Models for phase fluctuation of laser light in turbulent medium [8906-19]

M. Liu, X. Liu, Naval Aeronautical Engineering Univ. (China) and Key Lab. on Signal and Information Processing (China); M. Chen, Shandong Light Industry Engineering School (China); H. Wang, Naval Aeronautical Engineering Univ. (China) and Key Lab. on Signal and Information Processing (China)

8906 OC Research on receiving performance of receiver antenna array in free space optical communication system [8906-20]

Y. Wang, China Jiliang Univ. (China) and Harbin Institute of Technology (China); Q. Zhang, China Jiliang Univ. (China); J. Ma, L. Tan, Harbin Institute of Technology (China)

8906 OE An all-optical encryption system for multi-wave signals [8906-22]

J. Duan, Xi'an Telecommunication College (China) and Xi'an Institute of Optics and Precision Mechanics (China); Y. Wen, Xi'an Telecommunication College (China); T. Duan, Xi'an Institute of Optics and Precision Mechanics (China); X. Xie, Xi'an Telecommunication College (China) and Xi'an Institute of Optics and Precision Mechanics (China)

8906 OF An integrated all-optical encryption scheme for multi-wave $8 \times 80 \mathrm{Gbps}$ signal based on LibNO ${ }_{3}$ waveguide [8906-23]

J. Duan, Xi' an Telecommunication College (China) and Xi' an Institute of Optics and Precision Mechanics (China); Y. Wen, Xi'an Telecommunication College (China); T. Duan, Xi'an Institute of Optics and Precision Mechanics (China); X. Xie, Xi'an Telecommunication College (China) and Xi'an Institute of Optics and Precision Mechanics (China)

8906 OG The principle of space coherent laser communication based on Costas phase-locked loop [8906-24]

Y. Zheng, J. Zheng, S. Tong, H. Jiang, W. He, Changchun Univ. of Science and Technology (China)

$8906 \mathrm{OH} \quad$ Research on optimum local oscillator laser power of the space coherent laser communication [8906-25]

Y. Zheng, J. Zheng, S. Tong, H. Jiang, W. He, Changchun Univ. of Science and Technology (China)

8906 Ol The optimization of FHT-based ACO-OFDM atmospheric laser communication system in terms of PAPR reduction [8906-28]

Q. Guo, Y. Wei, Y. Duan, Beijing Univ. of Posts and Telecommunications (China)

$8906 \mathrm{OJ}$ The optimized structure design in improving the bandwidth of fast steering mirror [8906-29]

X. Zhai, F. Qi, H. Zhang, D. Jin, Changchun Institute of Engineering and Technology (China)

8906 OK Effect of the incidence angle to free space optical communication based on cat-eye modulating retro-reflector [8906-30]

L. Zhang, H. Sun, Y. Zhao, Y. Zheng, C. Shan, Academy of Equipment (China)

$8906 \mathrm{OL}$ The research of adaptive-exposure on spot-detecting camera in ATP system [8906-33]

F. Qian, J.-J. Jia, L. Zhang, J.-Y. Wang, Shanghai Institute of Technical Physics (China) 
8906 OM Study of acquisition technology of scanning in satellite-to-ground laser communication [8906-36]

J. Wang, Shanghai Institute of Technical Physics (China) and Shandong Univ. (China);

Y. Ma, Shanghai Institute of Technical Physics (China); W. Zhu, Shandong Univ. (China);

J. Qiang, Shanghai Institute of Technical Physics (China)

$89060 \mathrm{~N} \quad$ Aerosol optical depth characteristics in Yinchuan area [8906-37]

Y. Zhang, J. Mao, Z. Rao, F. Zhang, Beifang Univ. of Nationalities (China)

$890600 \quad$ SPM photon detection circuit design [8906-39]

T. Hu, Y. Zhao, Y. Liu, Electro-optical Information Security Control Lab. (China)

8906 OP Judd-Ofelt analysis and mid-infrared emission properties of $\mathrm{Ho}^{3+} \mathrm{Yb}^{3+} \mathrm{co}_{\text {-doped tellurite }}$ oxy-halide glasses [8906-40]

W. Zhang, Tongji Univ. (China); L. Rong, J. Ren, No.23 Research Institute of China Electronic Technology Corp. Group (China); Y. Jia, S. Qian, J. Lin, Tongji Univ. (China)

$89060 Q$ Experimental research of optical preamplifier receiver for RZ-DPSK based on delay interferometer [8906-42]

K. Zhang, Xi' an Institute of Optics and Precision Mechanics (China) and Univ. of Chinese Academy of Sciences (China); W. Wang, W. Zhao, Xi' an Institute of Optics and Precision Mechanics (China); X. Xie, F. Qian, Xi' an Institute of Optics and Precision Mechanics (China) and Xi' an Communication College (China)

8906 OR Simulation of optical pulse compression using parabolic pulse with linear chirp [8906-44] Z. Wang, The Armed Police Academy (China)

8906 OS Performance analysis of high altitude platform multi-hop optical communication with nonregenerative system [8906-47]

X. Wang, S. Zhao, L. Shi, Y. Li, G. Zheng, G. Zhao, Z. Zhu, Air Force Engineering Univ. (China)

8906 OT Research on characteristics of free-space optical communication link in weak atmospheric turbulence [8906-48]

L. Cui, Z. Hou, Anhui Institute of Optics and Fine Mechanics (China); F. Li, Anhui Institute of Optics and Fine Mechanics (China) and Electronic Engineering Institute (China)

8906 OU Effect of light source parameters on the polarization properties of the beam [8906-49] D. Liu, Changchun Univ. of Science and Technology (China); Y. Liu, Changchun Institute of Optics, Fine Mechanics and Physics (China); H. Jiang, Z. Liu, X. Zhou, H. Fang, Changchun Univ. of Science and Technology (China)

8906 OV $\quad 60 \mathrm{~nm}$ tunable multi-wavelength fiber laser with Brillouin gain loop [8906-51]

T. Wang, P. Zhang, Q. Jia, H. Jiang, Changchun Univ. of Science and Technology (China)

8906 OW Research on modulation properties of atmospheric wireless optical communication [8906-52]

H. Fang, Fundamental Science on Space-Ground Laser Communication Technology Lab.

(China); Y. Liu, Changchun Institute of Optics, Fine Mechanics and Physics (China); Z. Liu,

D. Liu, X. Zhou, Changchun Univ. of Science and Technology (China) 
8906 OX Scheduling algorithm for data relay satellite optical communication based on artificial intelligent optimization [8906-53]

W. Zhao, J. Zhao, S. Zhao, Y. Li, X. Wang, Y. Dong, C. Dong, Air Force Engineering Univ. (China)

8906 OY Echo scintillation index affected by cat-eye target's caliber in FSO communication [8906-54]

C. Shan, H. Sun, L. Zhang, Academy of Equipment (China)

$89060 Z$ Polarization phase shifting lateral shearing interferometer [8906-55]

L. Liu, A. Zeng, Shanghai Institute of Optics and Fine Mechanics (China) and Univ. of Chinese Academy of Sciences (China); L. Zhu, Shanghai Institute of Optics and Fine Mechanics (China); Q. Song, H. Huang, Shanghai Institute of Optics and Fine Mechanics (China) and Univ. of Chinese Academy of Sciences (China)

890610 The influence of atmospheric furbulence on IM/DD space optical communication system [8906-57]

A. Wei, Xi'an Institute of Optics and Precision Mechanics (China) and Univ. of Chinese Academy of Sciences (China); B. Han, W. Zhao, X. Xie, Xi' an Institute of Optics and Precision Mechanics (China); H. Hu, Y. Su, K. Zhang, Xi'an Institute of Optics and Precision Mechanics (China) and Univ. of Chinese Academy of Sciences (China)

890611 Two methods for measuring optical return loss of optical devices in laser propagation system [8906-58]

Q. Sun, J. Yan, Z. Zhang, The 41st Research Institute of China Electronics Technology Group Corp. (China)

890612 Research on UV scattering communication [8906-60]

K. Dong, Y. Lou, Y. Ding, S. Wang, Changchun Univ. of Science and Technology (China);

H. Wang, Military Representative Office of PLA 2nd Artillery in Beijing (China); H. Jiang, Changchun Univ. of Science and Technology (China)

890613 Active disturbance rejection controller of fine tracking system for free space optical communication [8906-61]

N. Cui, Y. Liu, X. Chen, Y. Wang, Harbin Institute of Technology (China)

890614 Design of laser monitoring and sound localization system [8906-64]

Y. Liu, X. Xu, Y. Dai, Y. Qiao, Changchun Univ. of Science and Technology (China)

890615 Research of narrow pulse width, high repetition rate, high output power fiber lasers for deep space exploration [8906-66]

Y. Tang, H. Li, Y. Wang, Z. Hao, D.-Y. Xiao, Changchun Univ. of Science and Technology (China)

890616 Study of laser scintilla characteristics in the atmosphere [8906-67]

Q. Fu, C. Chen, H. Jiang, Z. Liu, Z. Li, Changchun Univ. of Science and Technology (China)

890617 A novel fiber laser based on Rayleigh scattering feedback with a half-opened cavity [8906-68]

P. Zhang, T. Wang, Q. Jia, X. Liu, M. Kong, S. Tong, H. Jiang, Changchun Univ. of Science and Technology (China) 
890618 An ultra-narrow linewidth multiwavelength fiber laser without linear gain [8906-69] Q. Jia, T. Wang, P. Zhang, X. Liu, S. Tong, M. Kong, H. Jiang, Changchun Univ. of Science and Technology (China)

890619 Research on demodulation technology of atmospheric laser communication system base on CPolSK [8906-70]

$X$. Zhou, Changchun Univ. of Science and Technology (China); Y. Liu, Changchun Institute of Optics, Fine Mechanics and Physics (China); Z. Liu, D. Liu, H. Fang, M. Zheng,

Changchun Univ. of Science and Technology (China)

8906 1 A Monte Carlo simulation of laser pulse after underwater propagation [8906-71]

$X$. Hu, Shanghai Institute of Optics and Fine Mechanics (China) and Univ. of Chinese

Academy of Sciences (China); T. Zhou, Y. He, X. Zhu, W. Chen, Shanghai Institute of Optics and Fine Mechanics (China)

8906 1B Centroid measurement error of CMOS detector in the presence of detector noise for intersatellite optical communications [8906-72]

X. Li, Shanghai Institute of Satellite Engineering (China) and Harbin Institute of Technology (China); S. Zhou, Shanghai Institute of Satellite Engineering (China); J. Ma, L. Tan, T. Shen, Harbin Institute of Technology (China)

8906 1C Influence of sea-air interface on upward laser beam propagation [8906-75] T. Zhou, Y. He, X. Zhu, W. Chen, Shanghai Institute of Optics and Fine Mechanics (China) and Shanghai Key Lab. of All Solid-state Laser and Applied Techniques (China)

8906 ID Monte Carlo simulation for temporal characteristics of pulse laser propagation in discrete random medium [8906-79]

P. Wang, New Star Research Institute of Applied Technology (China); H. Yuan, New Star Research Institute of Applied Technology (China) and Key Lab. of Atmospheric Component and Optics (China); H. Mei, Key Lab. of Atmospheric Component and Optics (China); Q. Zhang, New Star Research Institute of Applied Technology (China)

8906 IE Comparison of dispersion compensation for DQPSK modulated formats in 100Gbps DWDM optical communication system [8906-80]

P. Zhang, D. Feng, W. Huang, Shandong Univ. (China); D. Jia, Tianjin Univ. (China)

$8906 \mathrm{lF}$ The influence of inhomogeneous gain on high-frequency phase of chemical laser beam [8906-83]

F. Fu, Xi'an Univ. of Arts and Science (China); B. Zhang, Sichuan Univ. (China)

$89061 \mathrm{G}$ An analysis on set-forward of laser guide active jamming [8906-84]

F. Liu, J. Ying, Mechanical Engineering College (China); M. Liu, 72465 Unit (China)

8906 1H A new optical antenna based on fiber coupling system and aspherical optical system [8906-85]

Y. Wang, S. Tian, Communication Univ. of China (China) 
890611 Optical signal transmission characteristics in slant path of blue-green laser communication links [8906-86]

Y. Ding, Univ. Key Lab. of Communication and Signal Processing (China) and Key Lab. of Communication Networks and Information Processing (China); L. Song, Q. Liu, Univ. Key Lab. of Communication and Signal Processing (China), Key Lab. of Communication Networks and Information Processing (China), and Dalian Univ. (China); C. Pan, Univ. Key Lab. of Communication and Signal Processing (China) and Key Lab. of Communication Networks and Information Processing (China)

8906 1J Design of compact off-axis four-mirror anastigmatic system for space communications [8906-87]

F. Zhao, Q. Sun, K. Chen, X. Zhu, S. Wang, G. Wang, X. Zheng, The 4lst Research Institute of China Electronics Technology Group Corp. (China)

8906 IK Improved beam steering efficiency of large deflection angle for periodic grating [8906-88] J. Zhou, L. Kong, F. Xiao, J. Zhuo, X. Yang, Univ. of Electronic Science and Technology of China (China)

$8906 \mathrm{lL}$ The research of high efficient optical fiber coupling technology in space laser communication [8906-92]

H. Wang, S. Tong, L. Zhang, H. Yang, Changchun Univ. of Science and Technology (China)

$89061 \mathrm{M}$ Design the RS $(255,239)$ encoder and interleaving in the space laser communication system [8906-93]

Y. Lang, S. Tong, Changchun Univ. of Science and Technology (China)

8906 iN Based on ground station adaptive optics for laser communications demonstration platform structures [8906-96]

L. Zhang, S. Tong, H. Wang, H. Yang, Changchun Univ. of Science and Technology (China)

890610 The red light VCSEL for network communication [8906-98]

Y. Deng, C. Yan, J. Shi, L. XU, Y. Feng, Y. Hao, Y. Zhao, Changchun Univ. of Science and Technology (China)

$89061 \mathrm{P}$ The research of high-speed clock in space laser communication [8906-105]

H. Yang, S. Tong, L. Zhang, H. Wang, Changchun Univ. of Science and Technology (China)

$89061 Q$ Real-time processor based on GPU for on-line performance evaluation of the 127-element adaptive optics system [8906-108]

H. Zhou, Institute of Optics and Electronics (China) and Univ. of Chinese Academy of Sciences (China); L. Zhou, Institute of Optics and Electronics (China)

8906 IR Measurement of atmospheric coherence length with differential movement of the image sensor [8906-109]

Y. Jia, S. Tong, Changchun Univ. of Science and Technology (China)

8906 is Average capacity for PCB propagation in atmospheric turbulence on Earth-space path [8906-111]

R. Yang, J. Hou, Y. Chen, Xidian Univ. (China); H. Chen, Guilin Univ. of Electronic Technology (China) 
8906 1T The research of methods to improve the control bandwidth for liquid crystal beam steering system [8906-113]

Y. Hao, Y. Huang, Q. Wu, W. Xiao, Institute of Optics and Electronics (China)

$89061 \mathrm{U}$ Design of ground testing systems which are compatible with two kinds of communication terminals [8906-116]

J. Jia, M. Yang, L. Zhang, J. Wu, Shanghai Institute of Technical Physics (China)

$89061 \mathrm{~V}$ The infrared laser atmosphere scattering communication study based on "Non-line-ofsight" [8906-117]

Z. Yang, D. Fan, X. Li, Y. Chen, Z. Feng, K. Sheng, G. Tao, D. Zhou, T. Hou, Southwest Institute of Technical Physics (China)

$89061 \mathrm{~W}$ Theoretical and experimental study on methods for increasing squeezed level in the generation of squeezed light [8906-1 18]

F. Feng, W. QU, Xi'an Institute of Optics and Precision Mechanics (China) and Univ. Of Chinese Academy of Sciences (China); J. Song, T. Zhang, Xi'an Institute of Optics and Precision Mechanics (China)

$89061 \mathrm{X}$ Vibration-induced jitter control in satellite optical communication [8906-119]

Z. Xue, B. Qi, Institute of Optics and Electronics (China) and Univ. of Chinese Academy of Sciences (China); G. Ren, Institute of Optics and Electronics (China)

$89061 \mathrm{Y} \quad \mathbf{H}_{\infty}$ mix sensitivity controller design based on GIMC for electro-optical stabilization and tracking system [8906-121]

Z. Liu, Institute of Optics and Electronics (China), Key Lab. of Beam Control (China), and Univ. of Chinese Academy of Science (China); Q. Bao, Institute of Optics and Electronics (China) and Key Lab. of Beam Control (China); Y. Xia, X. Liu, Institute of Optics and Electronics (China), Key Lab. of Beam Control (China), and Univ. of Chinese Academy of Science (China)

$89061 \mathrm{Z}$ Laser emitted through the off-axis Cassegrain antenna [8906-123]

S. Lei, X. Ke, J. Chen, Xi'an Univ. of Technology (China)

890620 Research of a portable atmospheric laser communication system [8906-124] W. Zeng, D. Li, S. Li, W. Tan, Z. Yi, Wuhan Mechanical College (China)

890621 The quick acquisition technique for laser communication between LEO and GEO [8906-126] L. Zhang, R. Zhang, Y. Li, L. Meng, X. Li, Changchun Univ. of Science and Technology (China)

890622 Acquisition and tracking system for 100km quantum entanglement distribution experiment [8906-132]

B. Qi, Institute of Optics and Electronics (China) and Univ. of Chinese Academy of Sciences (China); H. Chen, G. Ren, Y. Huang, Institute of Optics and Electronics (China); J. Yin,

J. Ren, Univ. of Science and Technology of China (China)

890623 Method of high speed flow field influence and restrain on laser communication [8906-133]

L. Meng, Changchun Univ. of Science and Technology (China) and Jilin Univ. (China);

C. Wang, C. Qian, S. Wang, L. Zhang, Changchun Univ. of Science and Technology (China) 
890624 Simulation approach for the design of radiation-hardened Erbium doped fiber amplifiers [8906-135]

J. Ma, Q. Liu, Y. Zhou, S. Yu, Harbin Institute of Technology (China)

890625 BER of Gaussian beam propagation in non-Kolmogorov turbulent atmosphere on slant path [8906-137]

R. Yang, Y. Chen, J. Hou, Xidian Univ. (China); H. Chen, Guilin Univ. of Electronic Technology (China)

890626 Math analysis of two-axis rotation-mirror course-tracking system for laser communication [8906-139]

X. Li, J. Sun, L. Bi, L. Zhang, L. Meng, Changchun Univ. of Science and Technology (China)

890627 Research on optic antenna of space laser communication networking [8906-140]

L.-X. Meng, Changchun Univ. of Science and Technology (China) and Jilin Univ. (China);

L. Li, L. Zhang, S. Zhao, H. Jiang, Changchun Univ. of Science and Technology (China)

$890628 \quad$ Multi-dimension pulse position modulation for RGB LEDs [8906-142]

Y. Zhang, X. Ke, M. Xie, Y. Kang, Xi'an Univ. of Technology (China)

890629 Real time basis-deviation measurement system based on BB84 module [8906-144] M. Zhang, J. Wu, L. Zhang, J. Jia, Z. He, S. Yang, F. Qian, J. Wang, Shanghai Institute of Technical Physics (China)

8906 2A BER of flat-topped Gaussian beam in slant path turbulent atmosphere [8906-145] F. LU, Y. Han, X. Han, R. Yang, Xidian Univ. (China)

8906 2B Multi-wavelength Erbium-doped fiber laser with single mode fiber and high nonlinear fiber [8906-146]

P. Wang, Y. Liu, X. Yu, Univ. of Electronic Science and Technology of China (China)

8906 2C Angular magnification method of liquid crystal optical phased array based on telescope system [8906-149]

F. Xiao, L. Kong, Univ. of Electronic Science and Technology of China (China)

8906 2D Research for the jamming mechanism of high-frequency laser to the laser seeker [8906-150]

X. Zheng, H. Zhang, Y. Wang, S. Feng, C. Zhao, Beijing Institute of Technology (China)

$89062 \mathrm{E} \quad$ Experiment research on uniformity of multi-beam illumination [8906-152]

Q. Sun, W. Wu, Y. Ning, B. Shu, National Univ. of Defense Technology (China)

$89062 \mathrm{~F}$ The aero optics effect on near space laser communication optical system [8906-157] Y. Hu, Y. Fu, H. Jiang, Changchun Univ. of Science and Technology (China)

$89062 \mathrm{G}$ Intensity correlation of Gaussian Schell-model beam on slant turbulent atmosphere [8906-158]

N. Xiang, Xian Yang Normal College (China) and Xidian Univ. (China); Z. Wu, Xidian Univ. (China); X. Hua, M. Wang, Xian Yang Normal College (China) 
$89062 \mathrm{H}$ Studies of energy Strehl ratio of a collimated Gaussian beam in turbulent atmosphere [8906-160]

Y. Yan, B. Liu, B. Zhou, D. Wu, Mechanical Engineering College (China)

Author Index

Proc. of SPIE Vol. $8906890601-11$

Downloaded From: https://www.spiedigitallibrary.org/conference-proceedings-of-spie on 26 Apr 2023 Terms of Use: https://www.spiedigitallibrary.org/terms-of-use 
Proc. of SPIE Vol. 8906 890601-12

Downloaded From: https://www.spiedigitallibrary.org/conference-proceedings-of-spie on 26 Apr 2023 Terms of Use: https://www.spiedigitallibrary.org/terms-of-use 


\section{Conference Committee}

Conference Chairs

Konstantin Vodopyanov, Stanford University (United States) and CREOL, The College of Optics and Photonics, University of Central Florida (United States)

Guofan Jin, Tsinghua University (China)

Songlin Zhuang, University of Shanghai for Science and Technology

(China)

Local Organizing Committee

Jiaqi Wang, Changchun Institute of Optics, Fine Mechanics and Physics (China)

Zuyan Xu, Technical Institute of Physics and Chemistry (China)

Zunqi Lin, Shanghai Institute of Optics and Fine Mechanics (China)

Dianyuan Fan, Shanghai Institute of Optics and Fine Mechanics (China)

Jingshan Jiang, Center for Space Science and Applied Research (China)

Liwei Zhou, Beijing Institute of Technology (China)

Shouhuan Zhou, North China Research Institute of Electro-optics (China)

Desheng Jiang, Wuhan University of Technology (China)

Jianquan Yao, Tianjin University (China)

Qingxi Tong, Institute of Remote Sensing and Digital Earth (China)

Junhao Chu, Shanghai Institute of Technical Physics (China)

Yongqi Xue, Shanghai Institute of Technical Physics (China)

Program Committee

Junhao Chu, Chair, Shanghai Institute of Technical Physics (China)

Jinxue Wang, Chair, Raytheon Company (United States)

Min Gu, Swinburne University of Technology (Australia)

Andreas Tünnermann, Friedrich-Schiller-Universität Jena (Germany)

Connie Chang, University of California, Berkeley (United States)

Shibin Jiang, AdValue Photonics Inc. (United States)

H. C. Liu, Shanghai Jiao Tong University (China)

Xiaocong Yuan, Nankai University (China)

Wei Shi, Tianjin University (China)

Min Qiu, Zhejiang University (China)

Nanjian Wu, Institute of Semiconductors (China)

Session Chairs

Keith E. Wilson, Jet Propulsion Laboratory (United States)

Jing Ma, Harbin Institute of Technology (China)

Liren Liu, Shanghai Institute of Optics and Fine Mechanics (China)

Huilin Jiang, Changchun University of Science and Technology (China)

Xizheng Ke, Xi'an University of Technology (China) 
Proc. of SPIE Vol. $8906890601-14$

Downloaded From: https://www.spiedigitallibrary.org/conference-proceedings-of-spie on 26 Apr 2023 Terms of Use: https://www.spiedigitallibrary.org/terms-of-use 


\section{Introduction}

We have had the great honor of organizing the Fifth International Symposium on Photoelectronic Detection and Imaging (ISPDI) in Beijing. It was truly a great pleasure for us to greet the more than 1,200 participants from many different countries attending ISPDI 2013! I firmly believe that the symposium will become an important international event in the field of photoelectronic detection and imaging technology.

ISPDI 2013 was sponsored by SPIE, The Optical Society, European Optical Society, and the Chinese Society of Astronautics, and was organized by the Photoelectronic Technology Committee, Chinese Society of Astronautics, Tianjin Jinhang Institute of Technical Physics, Science and Technology on Low Light Level Night Vision Laboratory, Science and Technology on Optical Radiation Lab. and Science and Technology on Electromagnetic Scattering Lab. There were 26 cooperating organizations that supported the meeting. Nearly 850 papers were accepted for presentation at ISPDI 2013, contributed by over 1,370 authors from more than 10 countries, including the United States, United Kingdom, Germany, France, Norway, Australia, Canada, Japan, Korea, Russia, China, and so on. We had seven plenary speeches and 135 famous scientists and experts from home and abroad to present the invited talks at 10 different conferences.

The purpose of ISPDI 2013 is to provide a forum for the participants to report and review the innovative ideas and up-to-date progress and developments, and discuss the novel approaches to applications in the field of photoelectronic detection and imaging. It is sincerely hoped that the research and developments in optical and photoelectronic fields will be promoted, and that international cooperation and the sharing of common interests will be enhanced.

On behalf of Prof. Konstantin Vodopyanov, and the other conference chairs, and the Organization Committee of ISPDI, I would like to heartily thank our sponsors and cooperating organizations for all they have done for the meeting. Thanks also to all the authors for their contributions to the proceedings, to all of the participants and friends for their interest and efforts in helping us make the symposium possible, to the Program Committee for their effective work and valuable advice, and especially the ISPDI 2013 Secretariat and the SPIE staff for their tireless effort and outstanding service in preparing the meeting and publishing the conference proceedings.

Guofan Jin 
Proc. of SPIE Vol. 8906 890601-16

Downloaded From: https://www.spiedigitallibrary.org/conference-proceedings-of-spie on 26 Apr 2023 Terms of Use: https://www.spiedigitallibrary.org/terms-of-use 